\title{
Use of didactic terminology by teachers at various stages of professional communication
}

\author{
Nina V. Bordovskaia ${ }^{1, *}$, Natalia A. Bochkina ${ }^{2}$, and Elena A. Koshkina ${ }^{3}$ \\ ${ }^{1}$ SPSU, Personal and Professional Development Psychology and Pedagogy Department, Faculty of Psychology, 199034, Saint \\ Petersburg, Russia \\ ${ }^{2}$ University of Edinburgh, the School of Mathematics, EH8 9YL, Edinburgh, Great Britain \\ ${ }^{3}$ Northern (Arctic) FU named after M.V. Lomonosov (Arkhangelsk), Pedagogy Department, Institute of the Humanities, SPSU, \\ Department of Psychology, 199034, Saint Petersburg, Russia
}

\begin{abstract}
The article is based on the study that involved 115 students acquiring professional pedagogical education and 115 practicing teachers. The article describes the process of emergence of individual conceptual and terminological frameworks during various stages of professional communication, i.e. training and pedagogical activity. Individual frameworks of concepts have been studied through comparison of interpretations of definitions of basic didactic concepts by respondents (a total of 3487 definitions have been processed), 353 concept maps, as well as wordings of professionally significant problems in which didactic terms were used as well (a total of 400 statements have been analyzed). Factors that influence the nature of how teachers use didactic terms in various instances of professional communication have been described.
\end{abstract}

\section{Introduction}

Usage of didactic concepts in professional pedagogical activity and communication is characterized by interdisciplinarity. On the one hand, it affects issues associated with implementation of principal functions (nominative, communicative, cognitive) of a scientific term as a component of scientific language [1]. On the other hand, usage of didactic terms is determined by deep psychological mechanisms and metal experience of a person. M. A. Kholodnaya emphasized close relationship between conceptual generalization and semantic structure of a word. Experiments have proven that semantic structure of a word has two levels - the level of object meaning (which defines direct or indirect relation of a word to certain real-life objects or phenomena) and the level of attitudinal and affective meaning (which reflects attitude of a person, their emotions and sensory experience towards content of the given word) [2].

\section{Problem statement}

In pursuit of efficient ways to improve the quality and results of education and training, teachers not only become familiarized with new scientific achievements, but also strive to actively implement those in their practical activities. Better mastering and proper usage of achievement in the field of didactics requires the ability to determine and duly consider particularities of alreadyformed conceptual and terminological framework, as well as factors that influence its renewal, in the course of professional training of teachers, their independent activity and during advanced training.

\section{Purpose of the study}

The purpose of the study was to characterize the conceptual and terminological frameworks with which future and practicing teachers operate. The following parameters were assessed:

- establishment of viewpoints when exploring the scope and contents of main didactic concepts;

- determination of the structure of main didactic concepts;

- use of didactic concepts when formulating problems associated with organization of the training process and assessment of its results, and when looking for ways to resolve said problems.

\section{Study methods}

The study was carried out using a set of methods that enable objective comparison of particularities that characterize usage of didactic terms at the stage of professional training and at the stage of professional activity:

- questionnaire survey was used to compile descriptions of principal social and professional characteristics of a sample of respondents;

\footnotetext{
Corresponding author: support.psy@spbu.ru
} 
- context analysis was performed to achieve the most accurate interpretation of definitions of didactic terms;

- the concept map method was used to establish existing relations between didactic concepts;

- the adapted "Problem Statement" technique (M.A. Kholodnaya, 1983) was used to determine the level of formedness of individual conceptual structures;

- "Thinking Style" questionnaire (adopted version by A.A. Alekseyev, L.A. Gromova (1993)) was used to identify the preferred thinking styles;

- content analysis, statistical methods (correlation, cluster analysis) were used to process results.

\section{Basis of the study}

The study involved 115 students of the Northern (Arctic) Federal University named after M. V. Lomonosov (Arkhangelsk), aged 18 to 30, where 17 are male and 98 are female ( $15 \%$ and $85 \%$ respectively); and 115 teachers of general academic schools of Arkhangelsk region, aged 20 to 65 , where 5 are male and 110 are female (4\% and $96 \%$ respectively). Thus, a total of 230 persons took part in the study.

\section{Results}

The adapted "Problem Statement" technique (M.A. Kholodnaya, 1983) was used to determine particularities of individual conceptual structures. Respondents were offered to state problems they come / may come across in the course of their future / current pedagogical activity. The obtained results were processed in two ways: to assess the complexity of problem statement and to assess the particularities of usage of didactic terms in the course of task solving.

Complexity of problem statement was rated based on the following scale:

- 0 points, if the problem is stated based on situational judgements or subjective reactions to the training process conditions in the educational institution;

- 1 point, if the problem is stated by identifying certain specific attributes and properties beyond situational problems that arise in the course of training;

- 2 points, if the problem is stated by connecting the given word to another, rather remote semantic field, while the scale of the problem is expanded to the level of community or country.

This task was completed by $70 \%$ of teachers and $81 \%$ of students; as a result, 400 statements with a total score of 151 points were obtained. 8 teachers and 13 students offered 34 statements with the highest level of complexity. Correlation analysis with Pearson's coefficient was used to determine linear correlation between main characteristics of the sample population of respondents and the task performance results. After statistical processing of quantitative data, the following particularities of individual conceptual frameworks of teachers were identified:

- work experience of a teacher has little effect on individual conceptual frameworks; for example, complexity of problem statement rather loosely depends on teachers' length of work $(r=0.35)$;

- the level of teacher's qualification has significant effect on the well-formedness of individual conceptual frameworks. For instance, strong correlation between was displayed between the highest and first qualification degrees and the number of teachers who stated complex problems $(r=0.83)$; strong correlation was also observed between the level of qualification and the number of points scored $(\mathrm{r}=0.95)$.

Such results, in our opinion, are due to the fact that validation of qualification level of Russian teachers is contingent upon them summarizing their professional experience. Such summary can be represented by the works being or having been published in specialized periodicals, speaking at scientific and tutorial conferences, advanced training courses, participation in professional competitions, etc. Summarizing own professional experience requires that the teacher possesses quite well-formed individual conceptual frameworks which are backed up by professional training and self-education, as well as by the need to self-improve in the professional field and in professional communication.

Based on statistical processing of students' responses, the following distinguishing features of individual conceptual frameworks were identified:

- there is a weak negative correlation between the length of training and the number of students who have stated complex problems $(\mathrm{r}=-0.32)$, as well as between the length of training and the number of points scored $(\mathrm{r}=-0.5)$;

- students' training results have significant effect on the well-formedness of individual conceptual frameworks. For instance, strong correlation between was displayed between training results and the number of students who have stated complex problems $(r=0.94)$; strong correlation was also observed between academic performance and the number of points scored $(r=0.78)$.

This can be explained by the fact that during initial training stages scientific and professional interests of students are yet not shaped, intellectual development is progressing, while thought process stereotypification resulting from professional activity and communication has not yet actively developed. Therefore, students experience less difficulties in stating complex problems. As the training period increases, students begin to focus on problems that will later be explored and presented in their graduation theses and projects, while the scale of problems that capture their interest becomes smaller. One of indicators of efficient training is the well-formedness of skills and abilities to analyze, systematize and formulate problems that arise in the course of fulfillment of professional duties. Therefore, students who perform highly and above average have demonstrated good ability to state more complex didactic problems.

The total size of active vocabulary of didactic terms used by respondents while completing the task amounted to 81 words and word-combinations with the total usage frequency of 220 units. Systematization of terms used while assessing the usage frequency allowed to make a number of conclusions regarding particularities of 
didactic terms usage by respondents in problem statements that are associated with the training process organization and evaluation of training results:

- maximum size (16 words) and maximum frequency of usage (86 units) are typical for terms associated with elements of the training process (grade, schedule, curriculum, training program, classroom, etc.). This particularity is equally typical for responses given by students and by teachers. Frequent usage of terms that stand for aspects of training organization and implementation directly correlates with data obtained based on evaluation of subjects of problem statements (see Table 1). This is explained by the significance of organizational conditions for the successful training process, as well as by respondents" interest in improving the training conditions (in case of students) or working conditions (in case of teachers). Here, students think and act based on their training experience, while teachers look up to their professional experience.

- most frequently used terms (32 units) in problem statements by teachers are those that stand for elements of educational content (educational standard, study subject, curriculum, training material, etc.). The reason for this can be the fact that one of principal professional activities of a teacher in the Russian general academic school is to adequately select training materials, and to independently develop training courses curricula.

- terms that used as names of pedagogical processes (training, teaching, etc.), elements of methodological support of the training process (methodological literature, methodological complex, etc.), forms of training (lesson, lecture, seminar, lab work, etc.), results of training (grade, quality of training, official evaluation, etc.) are characterized by equal distribution of size and usage frequency across groups of respondents. This can be explained by the fact that above terms have relatively stable meaning and play an important role in capturing elements of practical pedagogical activity and are more actively used in professional speech.

To assess particularities of how didactic terms are construed, students and teachers were offered to elaborate the meaning of 17 words and word-combinations that are directly related to organization and realization of the training process: demonstration, knowledge, academic performance evaluation, lecture, training method, skill, demonstrativeness, scientificity, training, grading, teaching, training aid, exercise, ability, learning, teaching information, exam. The terms have been selected based on the following requirements:

- stability, i.e. occurrence in modern Russian scientific, teaching literature, dictionaries and encyclopedias, and relatively stable definitions;

- the possibility to establish clear logical links between them.

As a result, 3487 definitions were obtained that were assigned to various levels in terms of statements" relation to the topic of didactics and based on the nature of how their generic and specific attributes are elaborated (in order to generalize the results and objectively interpret them, each level was assigned a certain number of points):

level 0 (0 points) - no definition; level 1 ( 1 point $)$ - affiliation of the term with theory or practice of training is not captured, while common or metaphorical meaning is explained;

level 2 (2 points) - affiliation of the term with theory or practice of training is captured indirectly, while specific examples are cited (subjects, actions);

level 3 (3 points) - affiliation of the term with theory or practice of training is clearly and directly captured, while the class of subject-matters defined by this term or individual specific attributes are clearly distinguished;

level 4 ( 4 points) - affiliation of the term with theory or practice of training is clearly and expressly demonstrated, generic and specific attributes of subjectmatters defined by this term are clearly captured.

The entire sample of respondents has been distributed across 4 groups based on the average score (b) that corresponded to the quality of elaboration of the term's content:

- low score group $(0 \leq b<1)-10 \%$ students and $0 \%$ teachers;

- below average group $(1 \leq b<2)-49 \%$ students and $33 \%$ teachers;

- above average group $(2 \leq b<3)-39 \%$ students and $59 \%$ teachers;

- high score group $(3 \leq b<4)-2 \%$ students and $8 \%$ teachers.

The fact that no teachers scored low enough to be placed in the low score group due to poor elaboration of terms' meanings, and that half of the teachers scored above average, demonstrates that teachers are rather wellfamiliarized with didactic terminology, while their professional experience allows them to more precisely and logically formulate the definition.

Obtained results showed that students are more likely to use associative techniques when defining terms, that they do not see a clear distinction between the common and the scientific/practical application of lexical units they were asked to analyze.

Comparison of obtained data with main characteristics of the sample allowed to identify a number of particularities. The students tend to demonstrate better use of terminology by the end of their training period; e.g. $48 \%$ of second-year students and $60 \%$ of third-year students demonstrated below average results, while 52\% of fourth-year students demonstrated above-average results. Fifth- and sixth-year students (graduate students) also demonstrate above-average scores. Such results can be explained by the fact that students' theoretical professional knowledge expands as the training progresses; plus, students become deeper involved in scientific and research activity which strengthens the need to search for new theoretical knowledge and to broaden the experience of their implementation. For teachers, this tendency is reversed: the quality of didactic terminology usage decreases as the working length increases up to 25 years. For teachers, use of terminology is associated with general intellectual faculties development mechanisms and with the gradual slowing down of such development as age progresses, as well as with increased influence of professional stereotypes in solving professional pedagogical tasks. 
Professional specialization indirectly affects the quality of usage of didactic terms. For example, students and teachers of humanities have equally demonstrated above-average quality of elaboration of concepts. This is due to the fact that their abilities and subjects of their activity allow them to more accurately express their thoughts in lexical terms and therefore to formulate and summarize their professional and personal experience.

In the course of training the connection between the thinking style and the quality of usage of didactic terms. For example, $25 \%$ students and $30 \%$ teachers who have demonstrated above-average quality of elaborating the meaning of didactic terms, demonstrated pragmatic thinking style which is characterized by using own experience as the basis, as well as using easily accessible sources of information and the tendency of focusing on getting quick results. Moreover, the quality of terms elaboration is influenced by respondents' involvement in scientific and research activity. Among students involved in research projects ( 71 persons), $51 \%$ have scored below average, $37 \%$ have scored above average, and $3 \%$ have scored highly. Among 44 teachers involved in scientific and educational projects, $32 \%$ have demonstrated below average results, $61 \%$ have demonstrated above average results, while $7 \%$ have scored highly.

Respondents were offered to come up with logical schemes using terms that they were previously asked to define. $80 \%$ of students and $70 \%$ of teachers have completed the task, and the results yielded 353 concept maps. Concept maps were evaluated based on the following parameters:

- type of concept map;

- type of logical links between concepts;

- identification of the conceptual and terminological core.

Concept maps were analyzed based on cognitive complexity criteria which is determined from the number of structural elements and links between them, openness and implicit dynamics of the map in general [3]. All concept maps were distributed across 4 groups:

a) image-based concept maps where images are used to represent links between concepts $(0.3 \%$ of students and none of teachers resorted to those);

b) linear concept maps, where concepts are organized in horizontal or vertical chains and hierarchic relations between them are not demonstrated (used by $21 \%$ students and $23.7 \%$ teachers);

c) tree-structures concept maps, where hierarchy of concepts (usually vertical) is captured and relations between them are demonstrated (used by $24.1 \%$ students and $13.3 \%$ teachers);

d) complex conceptual maps with multi-level structural organization - clear center and periphery, multilevel horizontal and vertical links, use of graphic forms for to represent hierarchy of concepts in the most accurate manner, etc. (used by $8.5 \%$ students and $9.1 \%$ teachers).

Data obtained from different concept maps were compared with such attributes of the sample population as year of training / length of work, specialization, academic performance / qualification level, and level of well-formedness of individual conceptual structures, which led to the following conclusions. Complexity of concept maps is dependent upon the length of training and professional activity. For instance, second-year students are more successful in developing tree-structured concept maps, while students of further years are more successful with linear concept maps; for teachers, treestructured maps are better developed by teachers with work experience between 26 and 30 years, while complex ones are better developed by those with 16 to 20 years of work experience. Most tree-structured maps were made by humanities teachers, while most complex maps were developed by physics and mathematics teachers. However, this factor did not play a role in selection of concept mapping by students.

In the course of the study, direct correlation was identified between selected type of concept mapping and respondent's status in terms of training performance or qualification level. Students who demonstrate high academic achievements, more often tend to use treestructured maps, those with average and above average training performance may equally use all three types of maps, while students with below average academic performance resort to linear maps. Teachers without qualification category usually use linear structures, those with category one use tree structure, while those with high qualification equally use tree and complex structures.

Type of logical links in concept maps has been determined based on classification suggested by M.E. Bershadskiy [4]. Most common type of logical link is serial, since $45 \%$ of concept maps have linear (horizontal) structure, while $56 \%$ are of tree-like concept maps, built based on the simplest two-level generic and specific relations.

Involvement in scientific research project plays a role in concept mapping for students only. Among them, 46\% have come up with complex concept maps. For teachers, this was true for $36 \%$ only. Students generally tend to more actively use scientific literature, successful understanding of which directly depends on proper comprehension of special terminology. Research activity of teachers is mostly based on comprehension of own professional experience and professional experience of colleagues, which requires consistent and firm knowledge of methodology of teaching the subject, while knowledge and proper use of didactic terminology plays a secondary role.

When processing concept maps with complex and branched tree structure, special attention was given to the presence of conceptual and terminological core, which is the largest concept in the structure to which all other concepts are directly or indirectly connected. Based on results of analysis, frequency of the core concept occurrence in concept maps was determined (some respondents used multiple terms as backbones): training (35 units), teaching (21 units), learning (13 units), knowledge (9 units), knowledge, ability, skill (7 units), teaching information (4 units), knowledge evaluation (1 unit), training method (1 unit). These data allow to conclude that the most significant terms are those with categorical meaning, i.e. "training", "teaching", "learning". Occurrence of these terms in individual conceptual and terminological structures is, on the one 
hand, due to the tradition of building the pedagogical education based on deep theoretical basis where pedagogical categorical framework must be mastered. On the other hand, it is due to the influence of experience resulting from professional communication and knowledge of typical situations that arise in the course of the training process.

\section{Conclusions}

Results obtained during the study allowed to revise the factors that play major roles in successful and effective usage of didactic terminology by teachers (future and practicing) in their professional communications:

- efficiency of training of students and qualification of teachers affect the level of well-formedness of individual frameworks of concepts;

- length of training of a student and length of work of a teacher determine the extent to which they can grasp the contents of didactic terms;

- professional pedagogical specialization indirectly influences the ability to formulate definitions of concepts and to develop conceptual schemes;

- involvement in scientific projects leads to more accurate elaboration of contents of terms and relations between them from scientific points of view.

The article has been prepared with financial support from the Russian Foundation for Humanities (Project No. 16-0600486).

\section{References}

1. V.M. Leichik, Terminology Studies: Subject, Methods, Structure (Izdatelstvo LKI, Moscow, 2007)

2. M.A. Kholodnaya, The Psychology of Intelligence: Research Paradoxes (Piter, Saint Petersburg, 2002) [In Rus]

3. E.L. Bogdanova, and O.E. Bogdanova, Tomsk State University Bulletin, 353, 161-165, 2011 [In Rus]

4. M.E. Bershadskiy, School Technologies, 2, 65-77, 2010 [In Rus] 